\title{
The IR absorption spectrum of water in microinclusions-bearing diamonds
}

\author{
Y. Weiss, I. Kiflawi and O. Navon \\ The Fredy and Nadine Herrmann Institute of Earth Sciences, \\ The Hebrew University of Jerusalem, Israel
}

\section{INTRODUCTION}

Microinclusions in fibrous and cloudy diamonds trapped high density fluids (HDFs) of diverse composition: saline, high-Mg carbonatitic and low-Mg carbonatitic to silicic melts/fluids (Navon et al., 1988; Weiss et al., 2009 and references therein). Upon cooling, secondary minerals crystallize and precipitate from the trapped HDFs; mica, apatite, carbonates and quartz were detected by IR spectroscopy (Chrenko et al., 1967; Navon et al., 1991; Schrauder and Navon, 1994; Zedgenizov et al., 2004; Tomlinson et al., 2007; Klein-BenDavid et al., 2007). Transmission electron microscopy (TEM) analyses confirm the presence of those phases as well as halides in the microinclusions (Guthrie et al., 1991; Walmsley and Lang, 1992a, b; Klein-BenDavid et al., 2006). Microinclusions of all compositions also carry residual low-density hydrous solutions which gives rise to the IR absorption bands at $\sim 3400$ and $\sim 1640 \mathrm{~cm}^{-1}$, corresponding to the $\mathrm{OH}$-stretching and $\mathrm{HOH}-$ bending vibration of water, respectively.

Navon (1991) noted that the OH-stretching band measured in cubic and coated diamonds resembles that of liquid water; while the high residual internal pressure in the microinclusions (Navon, 1991; Tomlinson et al., 2007) suggests that ice VI should be the stable phase at room temperature. Kagi et al. (2006) identified absorption of ice VI coexisting with liquid water in the stretching+bending combination band of molecular water at $\sim 5200 \mathrm{~cm}^{-1}$ Zedgenizov et al. (2006) pointed out that the shape and width of the $\mathrm{OH}$-stretching band is different in cuboid diamonds from Siberia and Congo. They suggested that the wider band of the Siberian diamonds is due to absorbance by different hydrous phases, including liquid water, ice and hydrous minerals.

In the present study we combine major-element spectroscopic and mineralogical data on the secondary assemblage in microinclusions in 47 fibrous diamonds from Africa, Siberia and Canada to explore the differences of the IR absorbance of water in microinclusions carrying HDFs of various compositions.

\section{SAMPLES and ANALYTICAL TECHNIQUES}

Forty seven fibrous diamonds carrying saline, high-Mg carbonatitic and low-Mg carbonatitic to silicic HDFs were selected for the present study. Except for the Ekati and the unknown diamonds, all other diamonds were described in previous studies (Table 1). The characteristics of the Ekati and the unknown sets will be published elsewhere.

IR spectra were measured on polished slabs using a Bruker IRscope II microscope coupled to a Nicolet 740 FTIR spectrometer (Globar source, $\mathrm{KBr}$ beamsplitter, MCT detector, $\mathrm{He}-\mathrm{Ne}$ laser). Spectra were taken in the range of $550-4000 \mathrm{~cm}^{-1}$ with resolution of $4 \mathrm{~cm}^{-1}$. After subtracting the diamond bands and the absorption due to nitrogen in the diamond matrix, a baseline correction was applied to the residual spectrum (spline fit to the lowest points). This procedure yields the residual spectrum due to absorption by the secondary phases in the microinclusions of each diamond. The shape, height and width of the $\mathrm{OH}$-stretching band at $\sim 3400 \mathrm{~cm}^{-1}$ and the $\mathrm{HOH}$-bending peak at $\sim 1650$ $\mathrm{cm}^{-1}$ were measured directly from this baseline corrected spectrum.

Table 1: Diamond origin and fluid characteristics

\begin{tabular}{|l|l|l|}
\hline $\begin{array}{l}\text { Number of } \\
\text { diamonds }\end{array}$ & Origin & Fluid type \\
\hline 9 & Ekati, Canada $^{1}$ & \\
1 & $\begin{array}{l}\text { DeBeers-Pool, RSA } \\
\text { Koffiefontein, RSA }\end{array}$ & Saline \\
2 & Udachnaya, Siberia $^{4}$ & \\
\hline 6 & Kankan, Guinea $^{5}$ & Hi-Mg carbonatitic \\
4 & Jwaneng, Botswana $^{6}$ & \\
9 & Kankna, Guinea $^{5}$ & \\
3 & Ekati, Canada $^{1}$ & Low-Mg carbonatitic to \\
2 & Udachnaya, Siberia $^{4}$ & silicic \\
3 & DeBeers-Pool, RSA $^{2}$ & \\
1 & Diavik, Canada $^{7}$ & \\
1 & Unknown (Botswana? $^{8}$ & \\
6 &
\end{tabular}

Data source: ${ }^{1} \mathrm{McNeill}$, Pearson and Weiss unpublished data; ${ }^{2}$ Weiss et al., 2008; ${ }^{3}$ Izraeli et al., 2001; ${ }^{4}$ Klein-BenDavid et al., 2009; ${ }^{5}$ Weiss et al., 2009; ${ }^{6}$ Schrauder and Navon (1994); ${ }^{7}$ Klein-BenDavid et al., 2007; ${ }^{8}$ Klein-BenDavid et al., 2010 


\section{$10^{\text {th }}$ International Kimberlite Conference, Bangalore - 2012}

High temperature IR spectra of three diamonds from Udachnaya and one from Kankan carrying microinclusions of high-Mg carbonatitic compositions were recorded using a Linkam THMS600 heating/cooling stage. The stage was clamped to the stage of the IRscope and connected to a TMS94 temperature programmer with temperature stability and accuracy of $\pm 0.1^{\circ} \mathrm{C}$. Spectra were taken between room temperature and $\sim 440^{\circ} \mathrm{C}$. The glass windows of the heating cell strongly absorb up to $2050 \mathrm{~cm}^{-1}$, thus in these experiments, only the absorbance due to the $\mathrm{OH}$-starching vibration could be recorded. After subtracting the diamond absorption and correcting the baseline, the changes in the shape of the $\mathrm{OH}$ stretching absorbance due to temperature increase were characterized.

We prepared pellets of $\mathrm{NaCl}$ and $\mathrm{KCl}$ and left them to absorb humidity for several days. Following, the absorbance of water molecules in these pellets was measured using the Bruker IRscope.

\section{RESULTS}

The width and the position of the $\mathrm{OH}$-stretching and $\mathrm{HOH}$-bending modes of water at $\sim 3400 \mathrm{~cm}^{-1}$ and $\sim 1650$ $\mathrm{cm}^{-1}$, respectively, vary with the composition of the microinclusions; the change in shape of the $\mathrm{OH}-$ stretching mode is prominent (Figure 1a). Low-Mg carbonatitic to silicic compositions show similar spectrum to that of pure water. However, in most cases, the $\mathrm{OH}$-stretching absorbance is higher than that of water between $\sim 3700-3500 \mathrm{~cm}^{-1}$ and $\sim 3200-2800 \mathrm{~cm}^{-1}$. In some diamonds, the $\mathrm{OH}$-stretching band has characteristic peak/shoulder situated at $\sim 3520-3600 \mathrm{~cm}^{-1}$. The width of the $\mathrm{OH}$-stretching band in diamonds carrying saline compositions is narrower compared to that of pure water, the position of the $\mathrm{HOH}$-bending vibration in such compositions shifts to lower energies (Figure 1b). In diamonds carrying high-Mg carbonatitic HDFs the width of the $\mathrm{OH}$-stretching absorption changes significantly, from $\sim 440$ to $\sim 860 \mathrm{~cm}^{-1}$. The increase of the band width is always towards lower wavenumbers and is accompanied by the appearance of a second small peak or a shoulder at $\sim 865 \mathrm{~cm}^{-1}$ together with the carbonate peak at $880 \mathrm{~cm}^{-1}$.

To characterize quantitatively the change in shape of the $\mathrm{OH}$-stretching absorption and relate it to the composition of the HDFs, we plotted the absorption ratio at $3200 \mathrm{~cm}^{-1}$ and $3400 \mathrm{~cm}^{-1}$ (as a measure of the peak position and shape) versus the width of the peak (Figure 2). The data points form a straight line $\left(\mathrm{R}^{2}=0.87\right)$ irrespective of the origin of the diamonds. The graph well separates the three groups of HDFs. It illustrates the similarity between the $\mathrm{OH}$-stretching mode of pure water and the low-Mg carbonatitic to silicic HDFs and the difference in shape of the three groups.
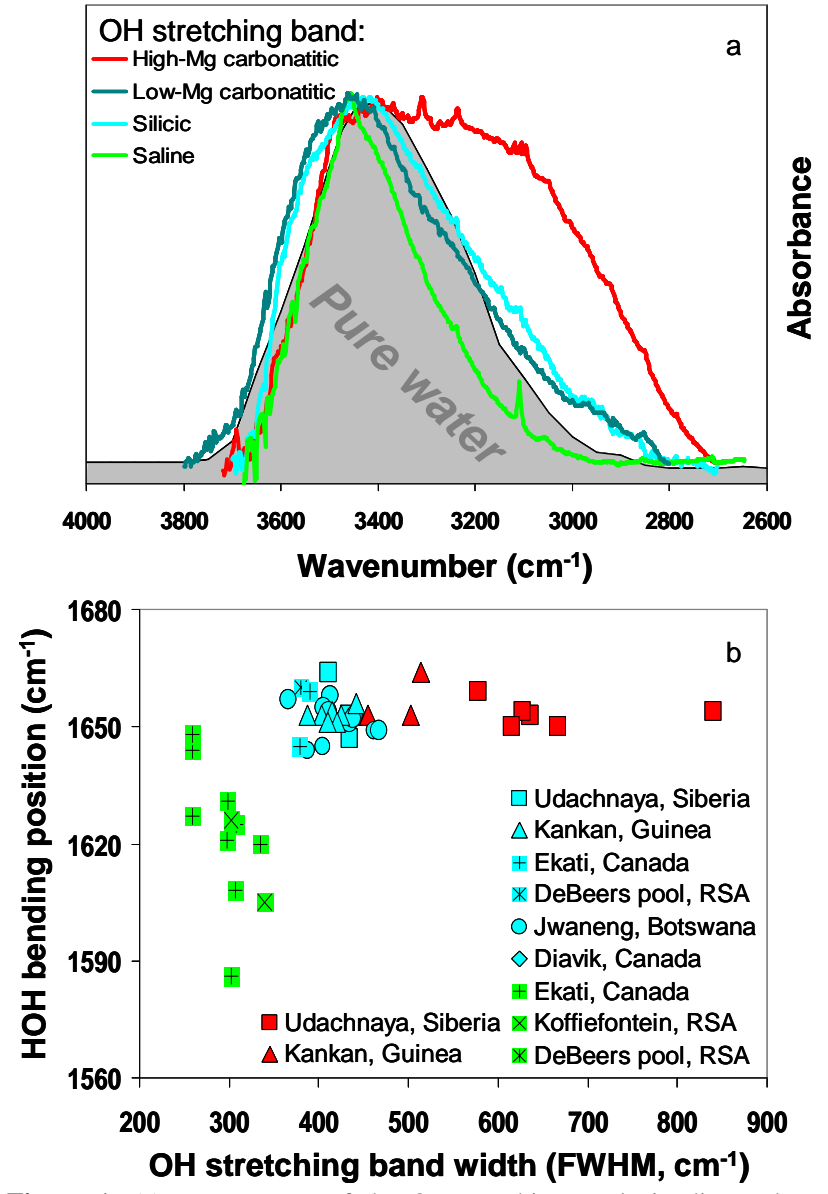

Figure 1: (a) IR spectrum of the $\mathrm{OH}$-stretching mode in diamonds carrying HDFs of diverse composition and in pure water. The pure water spectrum is from Venyaminov and Prendergast, 1997, we use it in all diagrams. (b) $\mathrm{HOH}$-bending position $v s$. the $\mathrm{OH}$-stretching band width (Full width at half-maximum, FWHM). Colors as in (a), except that data for low-Mg carbonatitic to silicic HDFs are all in turquoise.

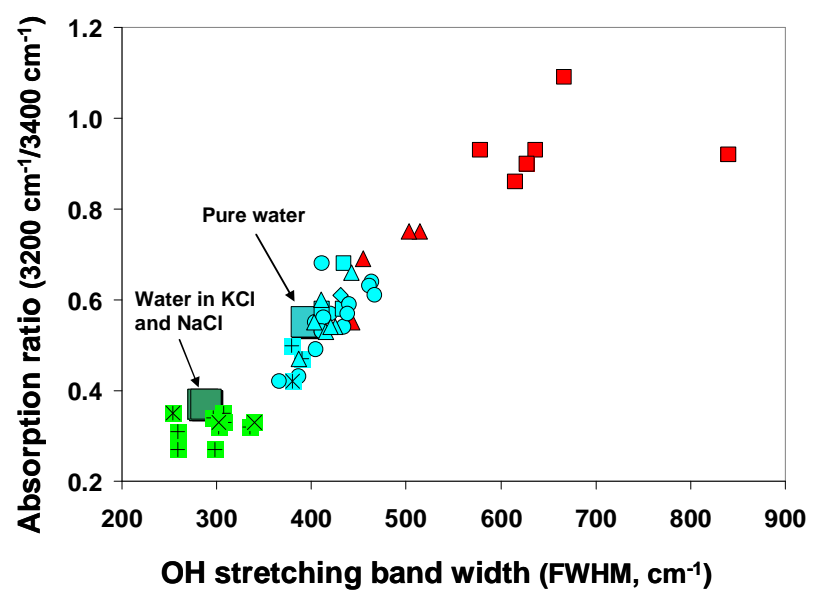

Figure 2: Absorption ratio $(3200 \mathrm{~cm}-1 / 3400 \mathrm{~cm}-1) v s$. the width of the $\mathrm{OH}$-stretching band. Overlapping green squares - water absorbed to $\mathrm{KCl}$ and $\mathrm{NaCl}$ pellets. 


\section{$10^{\text {th }}$ International Kimberlite Conference, Bangalore - 2012}

\section{DISCUSSION}

Considering the chemical composition of the microinclusions, we should expect the presence of relatively insoluble $\mathrm{Ca}-\mathrm{Mg}$ - and $\mathrm{Fe}$-carbonates, apatite, mica and quartz. However, the high abundance of potassium and sodium and the low chlorine content in the high-Mg carbonatitic and low-Mg carbonatitic to silicic compositions should lead to formation of $\mathrm{Na}$ - and $\mathrm{K}$ carbonates as well (Weiss et al., 2010) in equilibrium with a concentrated solution. In the saline compositions, $(\mathrm{Na}+\mathrm{K}) / \mathrm{Cl}<1$ and $\mathrm{Na}$ and $\mathrm{K}$ are fully compensated by $\mathrm{Cl}$. This and the low carbonate content make the formation of Na- and K-carbonates less likely.

Surveying the literature, we found that in water carrying high concentration of dissolved carbonates the $\mathrm{HOH}-$ bending vibration and the $\mathrm{OH}$-stretching mode shift to higher and lower wavenumbers, respectively. In contrary, high concentration of chloride ions leads to lower frequencies of the $\mathrm{HOH}$-bending vibration and higher ones in the $\mathrm{OH}$-stretching mode (Max and Chapados, 2001; Zedgenizov et al., 2006; Kagi et al., 2006; Venyaminov and Prendergast, 1997). In both cases the shift in the position of the peak is small and the general shape changes slightly in water-salt solutions. Therefore, the rather large difference in the shape of the $\mathrm{OH}$-stretching mode of diamonds carrying microinclusions of different composition is puzzling. We consider the contribution of solid $\mathrm{H}_{2} \mathrm{O}$, sheet silicates, salt-solvated water and hydrated carbonates in the microinclusions to explain these discrepancies.

\section{Solid $\mathrm{H}_{2} \mathrm{O}$ - Ice VI and Ice VII}

The high residual internal pressure of 1.3-2.1 GPa in the microinclusions, as inferred from the IR shift of quartz absorption bands (Navon, 1991; Tomlinson et al., 2007), suggest that the $\mathrm{H}_{2} \mathrm{O}$ phase in the microinclusions should be in the form of ice VI and/or ice VII (Bridgman, 1935; Datchi et al., 2000). Indeed, Kagi et al. (2000) measured the $\mathrm{OH}$-stretching plus $\mathrm{HOH}$-bending combination band of water at $\sim 5200 \mathrm{~cm}^{-1}$ in a cuboid diamond. They suggested that the difference in shape between the spectrum in the diamonds and that of liquid water can be explained by the presence of ice VI in the microinclusions. At the $3000-4000 \mathrm{~cm}^{-1}$ region, Ice VI and ice VII have characteristic IR spectra that are distinct in shape from that of liquid water; they are much narrower and shifted to somewhat lower energies (Figure 3).

The shape of the $\mathrm{OH}$-stretching band in the diamond spectra suggests that water in the microinclusions is present mostly in the form of liquid water. However, because water must carry dissolved halides and carbonates, its exact shape is not known and it is hard to determine whether absorption due to ice VI and/or ice
VII are present in the microinclusions based on the $\mathrm{OH}-$ stretching band alone (Figure 3).

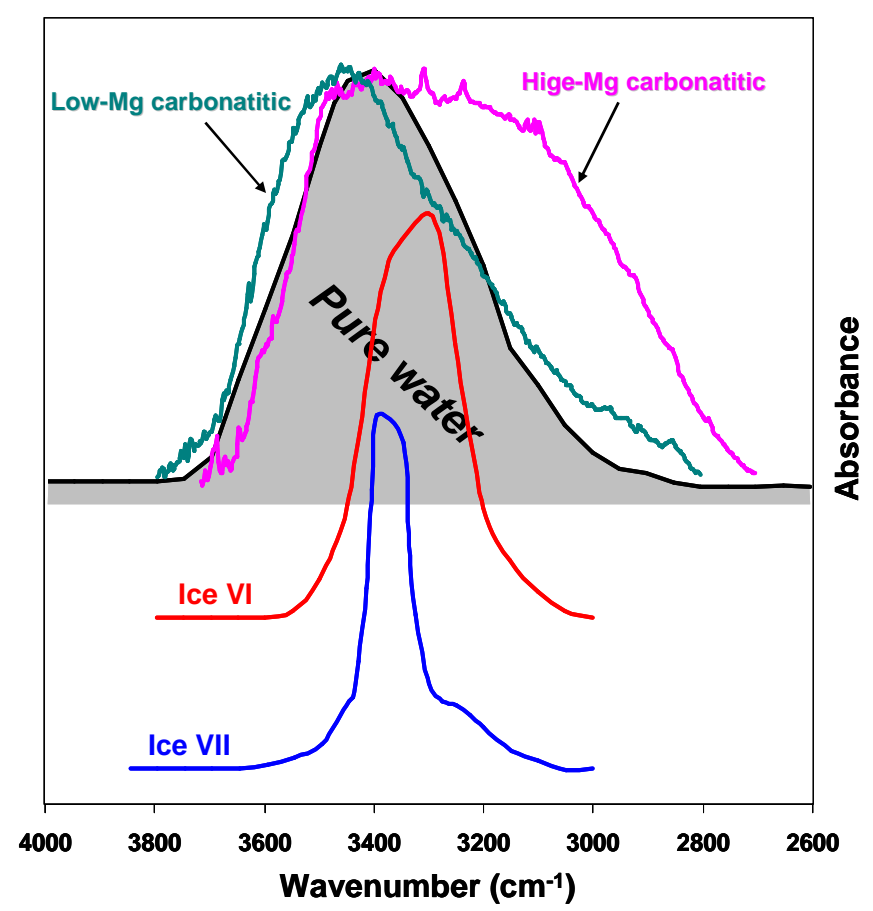

Figure 3: IR spectrum of liquid water, ice VI and ice VII and representative $\mathrm{OH}$-stretching spectra of high-Mg carbonatitic and low$\mathrm{Mg}$ carbonatitic HDFs. The ices spectra are digitized from Zedgenizov et al. (2006).

\section{Sheet silicates}

Secondary mica is usually detected by IR in diamonds carrying high-Mg carbonatitic and low-Mg carbonatitic to silicic HDFs (Klein-BenDavid et al., 2006, 2009; Weiss et al., 2009, 2010). The hydroxile groups of micas absorb at $\sim 3450-3650 \mathrm{~cm}^{-1}$ and may explain the extra absorption (relative to pure water) characterizing HDFs of low-Mg carbonatitic to silicic compositions (Figure 4). Different micas have similar IR spectrum and their main band, the Si-O stretching vibration, is usually situated at $\sim 1000 \mathrm{~cm}^{-1}$ (Farmer, 1974). Therefore, it is difficult to determine the exact composition of the mica in the microinclusions by IR alone. EPMA and TEM analyses suggest that the micas are of high-Si compositions midway along the phlogopite - Al-celadonite solid solution (Izraeli et al., 2001; Klein-BenDavid et al., 2006).

Figure 4 shows the spectrum of the $\mathrm{OH}$-stretching vibration of phlogopite, biotite and Fe-celadonite. None of the above micas provides a close match for the excess absorption of the diamonds relative to pure water and the spectrum of Al-celadonite is not available. However, the absorption ratio at $3600 \mathrm{~cm}^{-1}$ and $3400 \mathrm{~cm}^{-1}$ shows positive correlation with the $\mathrm{Al}_{2} \mathrm{O}_{3}$ content of the HDFs; 


\section{$10^{\text {th }}$ International Kimberlite Conference, Bangalore - 2012}

suggesting the control of mica on the intensity of the peak/shoulder at $\sim 3520-3600 \mathrm{~cm}^{-1}$ (Figure 5).

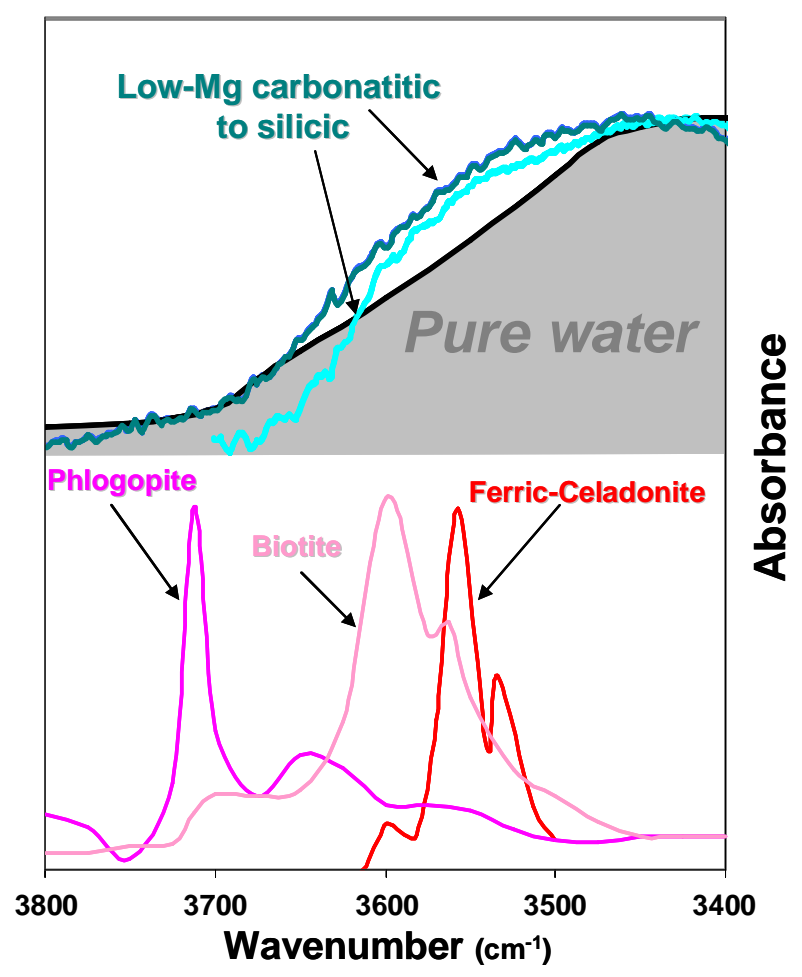

Figure 4: IR spectrum of the $\mathrm{OH}$-stretching mode in pure water and low-Mg carbonatitic to silicic HDFs between 3400 and $3800 \mathrm{~cm}^{-1}$ compared with $\mathrm{OH}$-stretching bands of phlogopite and biotite (Veder, 1964) and Fe-celadonite (Farmer, 1974).

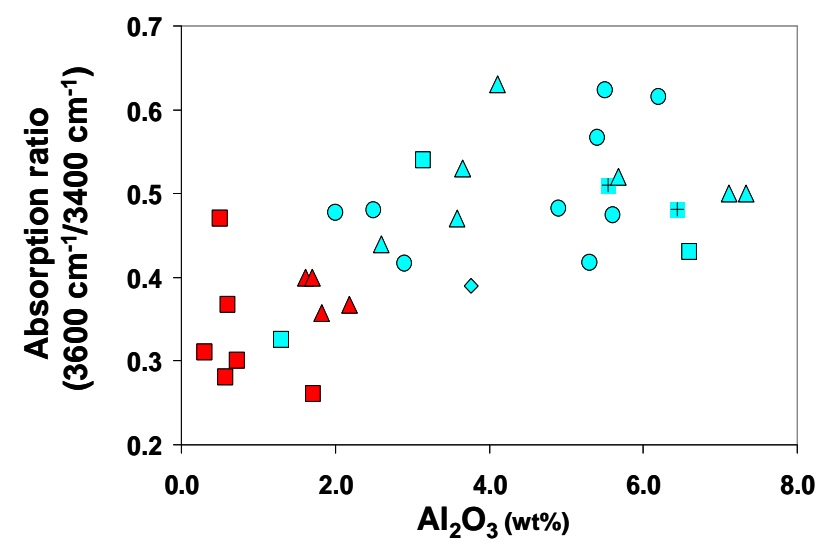

Figure 5: The absorption ratio at $3600 \mathrm{~cm}-1$ and $3400 \mathrm{~cm}-1$ vs. the $\mathrm{Al}_{2} \mathrm{O}_{3}$ content of high-Mg carbonatitic (red symbols) and low-Mg carbonatitic to silicic HDFs (turquoise symbols).

\section{Salt solutions and salt-solvated water}

IR spectra of concentrated chloride solutions are slightly different compared to that of pure water (Max and Chapados, 2001; Zedgenizov et al., 2006; Kagi et al.,
2006; Venyaminov and Prendergast, 1997). The HOHbanding vibration shows a small shift towards lower wavenumbers, while the $\mathrm{OH}$-stretching mode is shifted to higher wavenumbers and its width narrows. These differences are similar but less significant than those observed in the $\mathrm{OH}$-stretching mode in spectra of saline HDFs (Figure 1).

The affect on the shape of the $\mathrm{OH}$-stretching mode is stronger in the spectra of water absorbed by solid $\mathrm{NaCl}$ and $\mathrm{KCl}$ (salt-solvated water). In such cases, the affect of narrowing is more significant as well as the shift to higher wavenumbers (Max and Chapados, 2001). Figure 2 shows that the $\mathrm{OH}$-stretching mode characteristics of $\mathrm{NaCl}-$ and $\mathrm{KCl}$-solvated water pellets are similar to those of saline HDFs.

\section{Hydrated carbonates}

Carbonates dissolved in water produce only a small change in the position of the $\mathrm{OH}$-stretching mode (Zedgenizov et al., 2006) and can not explain the very wide band observed in the spectra of high-Mg carbonatitic HDFs (Figure 1). However, the spectrum of the $\mathrm{OH}$-stretching mode of water molecules in hydrous carbonates shows high absorption between 2700 and $3700 \mathrm{~cm}^{-1}$ (Catherine et al., 1977; White, 1971; http://rruff.info/). The presence of both liquid water and hydrated carbonates as part of the assemblage in microinclusions carrying high-Mg carbonatitic HDFs can explain the very wide band in the $\mathrm{OH}$-stretching mode of such HDFs (Figure 1). Hydrated potassium carbonate absorbs between 2600 and $3600 \mathrm{~cm}^{-1}$ with a maximum at $\sim 3100 \mathrm{~cm}^{-1}$ (Miller and Wilkins, 1952; Infrared Spectra Study Booklet). The second small peak or a shoulder at $\sim 865 \mathrm{~cm}^{-1}$ that appears together with the carbonate 880 $\mathrm{cm}^{-1}$ peak in diamonds carrying high-Mg carbonatitic HDFs suggest the present of such a phase in the microinclusions. The shape of the $\mathrm{OH}$-stretching band of high-Mg carbonatitic HDFs show significant change upon heating (Figure 6), reduction of the low energy absorption at $\sim 250^{\circ} \mathrm{C}$ may be explained by the breakdown of such hydrous carbonates.

\section{CONCLUSIONS}

The IR absorption of water changes according to the bulk composition of the trapped HDF in microinclusionsbearing diamonds. The main phase consists of liquid hydrous solution. The presence of ice in the microinclusions can not be ruled out or confirmed. The presence of mica can explain the absorption at $\sim 3700$ $3500 \mathrm{~cm}^{-1}$ while hydrated carbonates are probably responsible for absorbtion at $\sim 3300-2700 \mathrm{~cm}^{-1}$, which keads to the very wide band of the $\mathrm{OH}$-stretching mode in high-Mg carbonatitic HDFs. Although IR spectroscopy is insensitive to chlorides, the characteristic 


\section{$10^{\text {th }}$ International Kimberlite Conference, Bangalore - 2012}

shape of the $\mathrm{OH}$-stretching band in the spectrum of saline HDFs, may be used to identify saline fluids, based on FTIR alone.

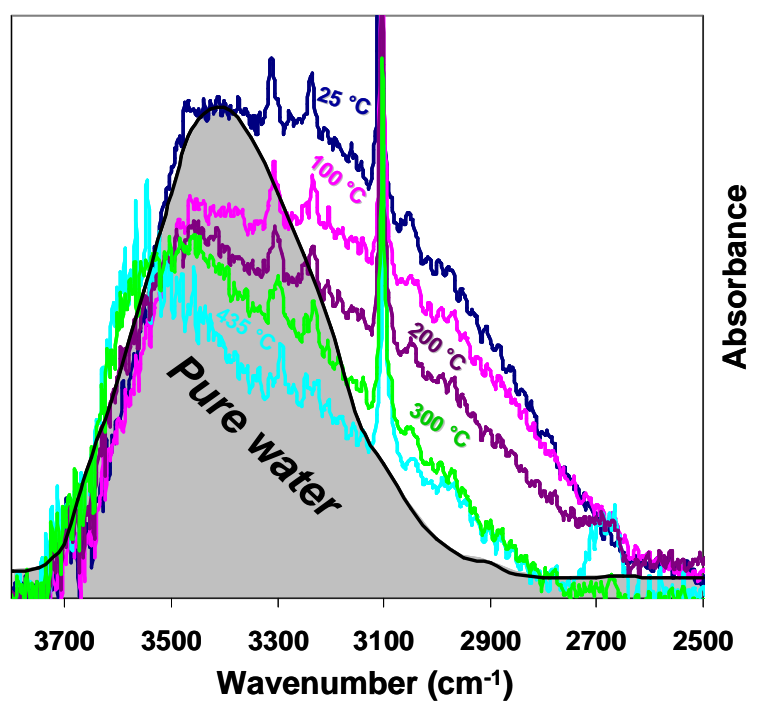

Figure 6: The $\mathrm{OH}$-stretching mode in the spectrum of a diamond carrying high- $\mathrm{Mg}$ carbonatitic $\mathrm{HDFs}$ upon heating to $435^{\circ} \mathrm{C}$. Increasing temperature is accompanied by a general decrease in the absorbance of the band. This decrease and the shift of the peak position to higher wavenumbers at $\sim 300^{\circ} \mathrm{C}$ and above are also observed in the spectrum of pure water at such temperature (Kazarian and Martirosyan, 2002). The significant reduction of the low energy absorption above $\sim 250^{\circ} \mathrm{C}$ may be explained by the decomposition of hydrated carbonates.

\section{References}

Bridgman P. W. (1935) The phase diagram of water to $45,000 \mathrm{~kg} / \mathrm{cm} 2$. J. Chem. Phys. 5, 964-966.

Catherine, H., Skinner, K., Osbaldiston, G. W., Wilner, A. N. Monohydrocalcite in a guinea pig bladder stone, a novel occurrence. American Mineralogist, 62: 273 - 277, 1977.

Chrenko, R.M., McDonald, R.S., Darrow, K.A., 1967. Infra-red spectra of diamond coat. Nature 214, 474-476.

Datchi F., Loubeyre P. and LeToullec R. (2000) Extended and accurate determination of the melting curves of argon, helium, ice (H2O), and hydrogen (H口 2). Phys. Rev. B 61(10), 6535-6546.

Farmer, V.C., 1974. The Infrared Spectra of Minerals. Mineralogical Society, London. pp. 539.

Guthrie, G.D., Veblen, D.R., Navon, O., Rossman, G.R., 1991. Submicrometer fluid inclusions in turbid-diamond coats. Earth Planet. Sci. Lett. 105 (1-3), 1-12.

Infrared Spectra Study Booklet, Iowa State University, Department of Chemistry, http://avogadro.chem.iastate.edu/Infrared/IR_Booklet.pdf

Izraeli, E.S., Harris, J.W., Navon, O., 2004. Fluid and mineral inclusions in cloudy diamonds from Koffiefontein, South Africa. Geochimica et Cosmochimica Acta 68, 2561-2575.

Kagi, H., Kiyasu, A., Akagi, T., Nara, M. and Sawaki, T. (2006) Near infrared spectroscopic determination of salinity and internal pressure of $^{-}$uid inclusions in minerals.. Applied Spectroscopy, 60, 430-436.

Kagi, H., Lu, R., Davidson, P., Goncharov, A.F., Mao, H.-K. and Hemley, R.J. (2000) Evidence for ice VI as an inclusion in cuboid diamonds from high P-T near infrared spectroscopy. Mineralogical Magazine, 64, 1089-1097.

Kazarian, S.G. and Martirosyan, G.G., 2002. ATR-IR spectroscopy of superheated water and in situ study of the hydrothermal decomposition of poly (ethylene terephthalate). Physical Chemistry Chemical Physics, 4, 3759-3763

Klein-BenDavid, O., Izraeli, E.S., Hauri, E., Navon, O., 2007. Fluid inclusions in diamonds from the Diavik mine, Canada and the evolution of diamond-forming fluids. Geochimica et Cosmochimica Acta 71, 723-744.

Klein-BenDavid, O., Logvinova, A.M., Schrauder, M., Spetius, Z.V., Weiss, Y., Hauri, E.H., Kaminsky, F.V., Sobolev, N.V., Navon, O., 2009a. High-Mg carbonatitic microinclusions in some Yakutian diamonds - a new type of diamond-forming fluid. Lithos 112, 648659.

Klein-BenDavid, O., Wirth, R., Navon, O., 2006. TEM imaging and analysis of microinclusions in diamonds: a close look at diamondgrowing fluids. American Mineralogist 91, 353-365.

Max J.J., and Chapados C., 2001. IR spectroscopy of aqueous alkali halide solutions: pure salt-solvated water spectra and hydration numbers. J. Chem. Phys., 115, 2664-2675.

Miller, F.A., and Wilkins, C.H., 1952. Infrared Spectra and Characteristic. Frequencies of Inorganic Ions. Anal. Chem., 24, 1253 to 1294.

Navon, O., 1991. High internal-pressures in diamond fluid inclusions determined by infrared-absorption. Nature 353, 746-748.

Navon, O., Hutcheon, I.D., Rossman, G.R.,Wasserburg, G.J., 1988. Mantle derived fluids in diamond micro inclusions. Nature 335, 784-789.

Schrauder, M., Navon, O., 1994. Hydrous and carbonatitic mantle fluids in fibrous diamonds from Jwaneng, Botswana. Geochimica et Cosmochimica Acta 58, 761-771.

Tomlinson, E.L., McMillan, P.F., Zhang, M., Jones, A.P., Redfern, S.A.T., 2007. Quartzbearing $\mathrm{C}-\mathrm{O}-\mathrm{H}$ fluid inclusions diamond: retracing the pressure-temperature path in the mantle using calibrated high temperature IR spectroscopy. Geochimica et Cosmochimica Acta 71, 6030-6039.

Vedder, 1964. Correlations between infrared spectrum and chemical composition of mica. The American mineralogist, 19, 736-767.

Walmsley, J.C., Lang, A.R., 1992a. On submicrometer inclusions I diamond coat-crystallography and composition of ankerites an related rhombohedral carbonates Mineral. Mag. 56 (385), 533-543.

Walmsley, J.C., Lang, A.R., 1992b. Oriented biotite Inclusions I diamond coat Mineral. Mag. 56 (382), 108-111.

Weiss, Y., Kessel, R., Griffin, W.L., Kiflawi, I., Klein-BenDavid, O., Bell, D.R., Harris, J.W., Navon, O., 2009. A new model for the evolution of diamond-forming fluids: evidence from microinclusionbearing diamonds from Kankan, Guinea. Lithos 112, 660-674.

Weiss, Y., Kiflawi, I., and Navon, O., 2010. IR spectroscopy: Quantitative determination of the mineralogy and bulk composition of fluid microinclusions in diamonds. Chemical Geology, 275, 1-2, 26-34.

White, W.B., 1971. Infrared characterization of water and hydroxyl ion in the basic magnesium carbonate minerals. The American mineralogist, 56, 46-53.

Zedgenizov D. A., Shiryaev A. A., Shatsky V. S. and Kagi H. (2006) Water-related IR characteristics in natural fibrous diamonds. Mineral. Mag. 70, 219-229.

Zedgenizov, D.A., Kagi, H.K., Shatsky, V.S., Sobolev, N.V., 2004. Carbonatitic melts in cuboid diamonds from Udachnaya kimberlite pipe (Yakutia): evidence from vibrational spectroscopy. Mineralogical Magazine 68, 61-73. 